\title{
Working with Survivors of Sexual Violence from a Sex-Positive Perspective
}

\author{
M. Candace Christensen \\ University of Texas San Antonio \\ Stephanie M. Hoover \\ Western Oregon University
}

Sexual violence is a widespread social problem with a destructive range of sexual behaviors that are committed without consent and results in physical, psychological, and social consequences (Jewkes et al., 2002). The Center for Disease Control found that approximately $20 \%$ of women in the U.S. will be sexually assaulted or experience an attempted assault in their lifetime and more than one in 10 men are victims of sexual violence (Black et al., 2011).

Survivors of sexual violence are at risk for a complex array of health problems. Two review articles (Van Berlo \& Eisnik, 2000; Weaver, 2009) summarized the impact on survivors' sexual health specifically. Van Berlo and Eisnik (2000) concluded that less sexual contact, diminished sexual pleasure, and fear of sex are prevalent among survivors. Specific to women, Weaver (2009) found that the research supported three primary areas of impact: (a) genital injury and sexually transmitted infections, (b) reproductive and sexual functioning, such as painful menstruation and sexual intercourse, and (c) sexual behaviors, including high-risk behaviors. The sexual health of sexual assault survivors who are men, queer, or transgender is understudied (Black et al., 2011; Rothman et al., 2011; Stotzer, 2009).

All facets of health are connected (Dahlberg \& Krug, 2002). Social aspects of the sexual trauma contribute to negative psychological outcomes. Specifically, the relationship between the offender and the survivor is related to the survivor feeling damaged, guilt, and shame (Van Berlo \& Eisnik, 2000). Intimate relationships between offender and survivor are shown to correlate with more severe psychological injuries, including dissociation and symptoms consistent with Borderline Personality Disorder (Freyd \& Birrell, 2013). Psychological injuries of sexual violence can include self-blame, generalized anxiety, posttraumatic stress disorder, depression, and attempted or completed suicide (Basile \& Smith, 2011; Chen et al., 2010; Tomasula et al. 2012; Weaver, 2009). Given these risks, we consider the role of sex-positivity to advance the health of sexual trauma survivors.

\section{Sex-Positive Approach}

Sex-positivity is defined as an open, accepting stance toward sexuality; this involves perceiving each person's sexuality as a unique, multifaceted set of values, experiences, and preferences (Williams et al., 2015). Sex-positivity also involves developing self-awareness about sexual values and assumptions one may have about sexual minorities or alternative sexual practices (Williams, 2012). Sex-positivity requires culturally relevant knowledge about sexual health and 
the development of skills in alignment with that knowledge (Robinson et al., 2002; Williams et al., 2015).

Sex-positivity intersects with sexual trauma treatment scholarship. Similar to a sex-positive approach, working with sexual trauma requires the practitioner to address each person's trauma as a distinctive, complex experience and develop culturally specific knowledge to treat sexual trauma (Brown, 2011a; McCarthy \& Breetz, 2010). From our investigation of sexual trauma and sex-positivity scholarship, three overlapping foci emerged (Brown, 2011a, 2011b; McCarthy \& Breetz, 2010; Robinson et al., 2002; Williams et al., 2015). We highlight three facets of a sexpositive approach: a) cultural competence, b) engaging in self-reflection, and c) obtaining education about sexual health and sexual diversity. These three foci will help practitioners develop a sex-positive approach in their work.

First, cultural competence was defined as an ability to be sensitive to the identities, values, and cultural norms that shape the way we see the world. Further, cultural competence is the ability to respect individual differences and develop creative responses that account for the strengths and needs of clients (Brown, 2011b; Robinson et al., 2002; Williams et al., 2015).

Second, the researchers described self-reflection as the process of exploring one's values and biases about a given topic (Brown, 2011b; McCarthy \& Breetz, 2010). This process allows practitioners to determine how their values and assumptions shape the way they work with people. Finally, the literature stressed obtaining knowledge and skills that are culturally relevant and specifically address sexual health, sexual diversity, and sexual trauma (McCarthy \& Breetz, 2010; Robinson et al., 2002; Williams et al., 2015). Training on these topics is not common in many helping professions, which means practitioners need to actively seek this type of education (Martin et al., 2007; McCarthy \& Breetz, 2010; Robinson et al., 2002).

\section{Sex-Positive Practice with Sexual Trauma Survivors}

We propose that practitioners address sexual trauma by using the sex-positive approach conceptualized above. Practitioners' development in culturally competent practice, selfreflection, and training specific to sexual health, sexual violence, and sex-positivity will enable them to provide appropriate sex-positive services to sexual assault survivors.

Cultural competence requires the practitioner to understand the context in which a traumatic event occurred and how the survivor views the event (Briere \& Scott, 2014; Brown, 2011b; McCarthy \& Breetz, 2010). For example, a person that negotiates with their partner to act out a rape fantasy, most likely, will leave that experience without psychological scarring. But, a person that is forced to have sex with their partner may consider that a traumatic event. What is the difference? In the first scenario, both parties negotiated and agreed upon the experience, and in the second scenario, there was no negotiation and the partner did not freely consent. Specific to sex-positivity, practitioners need to consider the context of clients' sexual values, sexual histories, and sexual interests (McCarthy \& Breetz, 2010; Robinson et al., 2002).

Engaging in self-reflection prompts the practitioner to assess biases they may have about their clients (Brown, 2011b). Practitioners need to reflect on their willingness to engage a sex-positive approach in treating survivors of sexual trauma (McCarthy \& Breetz, 2010; Robinson et al., 
2002; Williams et al., 2015). For example, a practitioner working with African American women that have experienced sexual trauma should consider any biases they may have about African American women tied to sexuality. Research demonstrates that historical images of Black women as hypersexual (e.g., the Jezebel stereotype)is linked to victim-blaming that targets Black women (West, 1995).

Practitioners need to seek information relevant to addressing sexual trauma with target populations (Brown, 2011a, 2011b; McCarthy \& Breeze, 2010). Treatment approaches to sexual trauma vary by populations. Practitioners must assess how race, class, gender, sexual orientation, ability, and religion, to name a few identities, impact a survivor's experience of the trauma (Brown, 2011b; Robinson et al., 2002). Using the previous example, evidence suggests that African American women that have survived sexual trauma use social support and religious coping to ameliorate the trauma (Bryant-Davis et al., 2011). However, research has also found a correlation between religious coping and higher levels of trauma symptoms (Harris et al., 2008). From a sex-positive perspective, it may be that the client has internalized sex-negative attitudes, which can be prevalent in many religions (Rubin, 1984). Internalized sex-negative attitudes may contribute to self-blame. For example, a survivor may view the trauma as punishment or ordained by God.

Practitioners also need to understand the importance of language and word choice in processing the trauma (Briere \& Scott, 2014; Brown, 2011b). A sexual assault survivor whose first sexual experience was the assault may define virginity as a first experience with penile-vaginal intercourse, the cultural label. The survivor may choose to reject that cultural definition as it applies to their assault, identify as a virgin, or reject the notion of virginity entirely. When survivors claim their own understanding of sex and sexuality, survivors are able to reshape their understanding of the assault. Further, this practice can ameliorate the self-blame that is common for many survivors. By reducing self-blame, clients can begin to see that a culture of sexual violence is to blame for the trauma (Brown, 1994, 2011b). Clients may benefit from increased consciousness about how social constructs of sexuality have made sexual violence acceptable (Brown, 2011b; Rubin, 1984).

Specific to sex-positive training, practitioners can access resources to bolster their knowledge of sexual health and sexual diversity. One resource is the American Association of Sexuality Educators, Counselors, and Therapists (AASECT) Sexual Attitude Reassessment Training (SAR; AASECT, 2015). This training includes comprehensive sexual education, which includes information about sexual minority communities (LGBTQ), bondage-domination-sadismmasochism (BDSM), fetish, and kink. Further, several organizations exist that provide education about sexuality from a sex-positive perspective: (a) Center for Positive Sexuality in Los Angeles, (b) Center for Sex Positive Culture in Seattle, (c) Community-Academic Consortium for Research on Alternative Sexualities (CARAS), and (d) The Kinsey Institute.

In terms of skills, practitioners need to assess potential interventions from a sex-positive perspective. Three questions to determine if a treatment approach is sex-positive are: (a) Does the approach encourage the client to explore their sexual values and understanding of healthy sexuality? (b) Does the approach encourage a holistic exploration of sexuality from culturally relevant and strengths-based perspective? (c) Is the approach flexible and client-centered such 
that it allows for the client's ongoing processing of the trauma? Possible approaches to sexpositive therapy include intersystem (Weeks, 1994, 2005), feminist (Brown, 1994), sexual health model (Robinson et al., 2002), and narrative therapy (White \& Epston, 1990). First, the intersystem approach highlights the interaction of biological, mental health, social relationships, family of origin, and sociocultural factors. Intersystem therapy tends to utilize family and couple formats; this approach may be culturally relevant for clients who have a relational focus with their sexuality. Second, feminist therapy is consistent with sex-positivity's focus on the social construction of sexuality. In particular, feminist consciousness-raising groups (Marecek \& HareMusten, 1991) could help survivors with multiple oppressed identities understand the sociocultural context that perpetuates their experiences of oppression. Third, the sexual health model emphasizes comprehensive and culturally relevant sexuality education, a holistic approach to sexuality, and communication about sex (Robinson et al., 2002).

The last approach, narrative therapy, is described in further detail because it is not often associated with sex-positivity and sexual trauma. Narrative therapy assumes that individuals have the capacity to overcome life challenges by rewriting negative scripts into positive, solution-oriented scripts (White \& Epston, 1990). Returning to the earlier example, a religious, African American woman that has experienced sexual trauma may have internalized negative scripts about her sexuality and the sexual violence, which are based upon the Jezebel stereotype and religious attitudes about sex (Bryant-Davis et al., 2011; West, 1995). Narrative therapy will help this survivor rewrite those scripts to embody sex-positivity. The first step is to work with the client to name the problem in a way that exists outside of the individual, for example, "judgments about sex" or "the anti-pleasure monster." Invite the client to use all the senses to describe the problem. For example, the anti-pleasure monster might hide in one's pocket and smell like perfume. Ask the client to focus on how the problem is causing disruption and negative consequences. Perhaps the anti-pleasure monster shows up in the shower or when wanting to masturbate. Next, encourage the client to remember and discuss moments when the client was able to overcome the problem; i.e., how has the client transformed other monsters? Invite the client to gather an inventory of times when the client overcame other problems, conveyed competence, and enjoyed successes. With this historical evidence, the client recreates the problem narrative into a positive, solution-oriented view of success. The new narrative may involve the client doing something to the monster and creating a new image of her sexuality.

\section{Conclusion}

Sexual violence is a pervasive social problem that impacts everyone, regardless of race, class, or gender (García-Moreno et al., 2002). Sexual violence may have a significant impact on the physical, psychological, and social health of survivors, which all shape the sexual well-being of survivors. A sex-positive framework could help survivors address the trauma and increase their consciousness of how social constructs of sexuality have made sexual violence acceptable. To become a sex-positive practitioner, professionals need to understand cultural competence, engage in self-reflection and sex education, as well as provide sex-positive interventions.

\section{References}


American Association of Sexuality Educators, Counselors, and Therapists. (n.d.). Sexual attitude reassessment training. Retrieved from: http://www.aasect.org

Basile, K. C., \& Smith, S. G. (2011). Sexual violence victimization of women: Prevalence, characteristics, and the role of public health and prevention. American Journal of Lifestyle Medicine, 5, 407-417.

Black, M. C., Basile, K. C., Breiding, M. J., Smith, S. G., Walters, M. L., Merrick, M. T., \& Stevens, M. R. (2011). The National Intimate Partner and Sexual Violence Survey (NISVS): 2010 Summary Report. Atlanta, GA: National Center for Injury Prevention and Control, Centers for Disease Control and Prevention.

Briere, J. N., \& Scott, C. (2014). Principles of trauma therapy: A guide to symptoms, evaluation, and treatment. Thousand Oaks, CA: Sage Publications.

Brown, L. S. (1994). Subversive dialogues: Theory in feminist therapy. New York: Basic Books.

Brown, L. S. (2011a). Becoming a trauma-aware therapist: Definitions and assessment. Washington, DC: American Psychological Association. Retrieved from: http://www.continuingedcourses.net

Brown, L. S. (2011b). Emotional and cultural competence in the trauma-aware therapist. Washingon, DC: American Psychological Association. Retrieved from: http://www.continuingedcourses.net

Bryant-Davis, T., Ullman, S.E., Tsong, Y., \& Gobin, R. (2011). Surviving the storm: The role of social support and religious coping in sexual assault recovery of African American women. Violence Against Women, 17, 16011618.

Chen, L. P., Murad, M. H., Paras, M. L., Colbenson, K. M., Sattler, A. L., Goranson, E. N., \& Zirakzadeh, A. (2010). Sexual abuse and lifetime diagnosis of psychiatric disorders: Systematic review and meta-analysis. Mayo Clinic Proceedings, 85, 618-629.

Dahlberg, L. L., \& Krug, E. G. (2002). Violence-A global public health problem. In E. Krug L. L. Dahlberg, J. A. Mercy, A. B. Zwi, \& R. Lozano (Eds.), World report on violence and health (pp. 1-56). Geneva, Switzerland: World Health Organization. Retrieved from: http://www.who.int/violence_injury_prevent ion/violence/world_report/en/

Freyd, J. J., \& Birrell, P. J. (2013). Blind to betrayal. New York, NY: Wiley.
García-Moreno, C., Jansen, H. A. F. M., Ellsberg, M., Heise, L., \& Watts, C. (2005). WHO multi-country study on women's health and domestic violence against women. Geneva, Switzerland: World Health Organization. Retrieved from: http://www.who.int/gender/violence/who_m ulticountry study/en/

Harris, J., Erbes, C., Engdahl, B., Olson, R., Winskowski, A., \& McMahill, J. (2008). Christian

religious functioning and trauma outcomes. Journal of Clinical Psychology, 64, 17-29.

Jewkes, R., Sen, P., \& García-Moreno, C. (2002). Sexual violence. In E. Krug, L.L. Dahlberg, J.A. Mercy, A.B. Zwi, \& R. Lozano (Eds.), World report on violence and health (pp. 213-239). Geneva, Switzerland: World Health Organization. Retrieved from: http://www.who.int/violence_injury_prevent ion/violence/world_report/en/

Marecek, J. T. \& Hare-Musten, R. T. (1991). A short history of the future: Feminism and clinical psychology. Psychology of Women Quarterly, 15, 521-536.

Martin, S. L., Young, S. K., Billings, D. L., \& Bross, C. C. (2007). Health care-based interventions for women who have experienced sexual violence: A review of the literature. Trauma, Violence, \& Abuse, 8 , 3-18.

McCarthy, B. W., \& Breetz, A. (2010). Confronting sexual trauma and enhancing adult sexuality. In S. B. Levine, C. B. Risen, \& S. E. Althof (Eds.), Handbook of clinical sexuality for mental health professionals (pp. 295-310). New York: Routledge.

Robinson, B. E., Bockting, W. O., Simon Rosser, B. R., Miner, M., \& Coleman, E. (2002). The sexual health model: Application of a sexological approach to HIV prevention. Health Education Research, 17, 43-57.

Rothman, E. F., Exner, D., \& Baughman, A. L. (2011). The prevalence of sexual assault against people who identify as gay, lesbian, or bisexual in the United States: A systematic review. Trauma, Violence, \& Abuse, 12, 55-66.

Rubin, G. (1984). Thinking sex: Notes for a radical theory of the politics of sexuality. In C.S. Vance (Ed.), Pleasure and danger: Exploring female sexuality, (pp. 267-319). London, UK: Routledge.

Stotzer, R. L. (2009). Violence against transgender people: A review of United States data. 
Aggression and Violent Behavior, 14, 170179.

Tomasula, J. L., Anderson, L. M., Littleton, H. L., \& Riley-Tillman, T. C. (2012). The association between sexual assault and suicidal activity in a national sample. School Psychology Quarterly, 27, $109-119$.

Van Berlo, W., \& Ensink, B. (2000). Problems with sexuality after sexual assault. Annual Review of Sex Research, 11, 235-257.

Weaver, T. L. (2009). Impact of rape on female sexuality: Review of selected literature. Clinical Obstetrics and Gynecology, 52, 702-711.

Weeks, G. (1994). The marital-relationship therapy casebook: Theory \& application of the intersystem model. New York: Routledge.

Weeks, G. R. (2005). The emergence of a new paradigm in sex therapy: Integration. Sexual and Relationship Therapy, 20, 89-103.

West, C. M. (1995). Mammy, Sapphire, and Jezebel: Historical images of black women and their implications for psychotherapy. Psychotherapy, 32, 458-466.

White, M., \& Epston, D. (1990). Narrative means to therapeutic ends. New York: WW Norton \& Company.

Williams, D.J. (2012). Sexual diversity in patients: The importance of being nonjudgmental. Australian Family Physician, 41, 745.

Williams, D. J., Thomas, J. N., Prior, E. E., \& Walters, W. (2015). Introducing a multidisciplinary framework of positive sexuality. Journal of Positive Sexuality, 1, 611. 